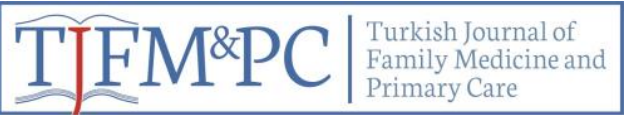

Original Research / Özgün Araştırma

\title{
Evaluation of Menopausal Perception and Health Literacy in Women Menopausal Period with Chronic Disease
}

\author{
Kronik Hastalığı Olan Menopozal Dönemdeki Kadınlarda Menopoz Algısı ve Sağlık Okur Yazarlığının \\ Değerlendirilmesi
}

Derya Kaya Şenol ${ }^{* 1}$, Özlem Bulantekin Düzalan ${ }^{1}$,Sibel Sarıkaya², Büşra Özen ${ }^{2}$

\begin{abstract}
Introduction: It is important to note that individuals with low health literacy are more likely to understand health risks, assess different treatment opportunities, have less ability to comply with health care recommendations, use fewer preventive health services, increase spending with unnecessary hospital admissions, decrease the frequency of early diagnoses and higher morbidity and mortality rates. Methods: Çankırı State Hospital was carried out with 175 women who were inpatient in the internal medicine clinic and were in menopausal period. Before starting to work, permission was obtained from Çankırı Karatekin University Ethics Board and Çankırı State Hospital. Data was analyzed using the IBM SPSS Statistics Version 20 package program. Results: Among the women in the study; $32.5 \%$ were primary school graduates, $37.1 \%$ had lower income and $94,3 \%$ were health insurance. The average age of first marriage was $17,5 \pm 3,6$. When the obstetric characteristics were examined, mean menarche age was $13,1 \pm 1,9$, menopause age was $47,1 \pm 5,8$, number of pregnancy was 5,5 $\pm 3,3$. Diabetes, $19.6 \%$ Diabetes + Hypertension, $23.4 \%$ Hypertension were seen in the first three ranks when participants were diagnosed with chronic diseases. It was found out that $91,4 \%$ of the women were using drugs continuously and $9,1 \%$ were using cigarettes. In the study, $42.9 \%$ of women regard menopause as a natural process and $61,1 \%$ of them did not receive any information about menopause. When educational status is examined in terms of health literacy scale; $(\mathrm{p}=0,001)$ were significantly higher than the mean scores of the participants who graduated from high school and over. The health literacy score of the women with high income in the survey was found to be statistically significantly higher. $(p=0,001)$. The health literacy score of the participants who did not use a continuous drug was significantly higher than the drug users $(\mathrm{p}=0,001)$.

Conclusion: It is seen that factors such as education, and high level of income in menopausal women with chronic illness affect health literacy positively.
\end{abstract}

Key words: Health literacy, chronic illness, menopausal period, woman

ÖZET

Giriş: Sağlık okuryazarlığı düşük olan bireylerin, sağlık risklerini anlama, sağlık bakım önerilerine uyma konusunda yeteneklerinin daha az olduğu, koruyucu sağlık hizmetlerini daha az kullandığı, gereksiz hastane başvuruları ile harcamalarda artışa, erken teşhis edilebilen durumların sıklığında azalmaya, yüksek morbidite ve mortalite oranlarına yol açtığı belirtilmektedir. Amaç: Çalışma, menopozal dönemdeki kadınların sağlık okuryazarlığı durumlarını belirlemek için yapılmıştır. Metod: Tanımlayıcı tipteki bu çalışma; Çankırı Devlet Hastanesi Dahiliye kliniğinde yatarak tedavi gören ve menopozal dönemde olan 175 kadınla yürütülmüştür. Çalışmadan elde edilen veriler, IBM SPSS Statistics Version 20 paket programı ile analiz edilmiştir. Bulgular: Araştırma kapsamındaki kadınların; \%32.5'inin ilkokul mezunu, \% 37,1'inin gelirinin giderden az ve \%94,3'ünün sağllk güvencesinin olduğu saptanmıştır. Kadınların ilk evlilik yaş ortalaması 17,5 $\pm 3,6$ idi. Obstetrik özellikleri incelendiğinde, ortalama ilk adet yaşının 13,1

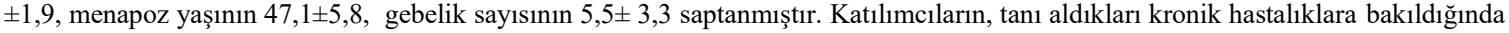
ise ilk üç sırada \%19,8 ile diyabet, \%19,6 ile diyabet+hipertansiyon, \%23,4 ile hipertansiyon görülmektedir. Kadınların \% 91,4'ünün sürekli kullandığı bir ilacı olduğu, \% 9,1'inin sigara kullandığı belirlenmiştir. Çalışmada, kadınların \%42,9'unun menopozu doğal bir süreç olarak gördüğü, \% 61,1'inin bu döneminde menopoza yönelik bilgi almadığı belirlenmiştir. Sağlık okur-yazarlığı ölçeği bakımından eğitim durumu incelendiğinde; lise ve üzeri düzeyde mezun olan katılımcıların puan ortalamalarının anlamlı derecede yüksek olduğu saptanmıştır ( $\mathrm{p}=0,001)$. Araştırmada, geliri fazla olan kadınların, sağlık okur-yazarlığı puanı istatistiksel olarak anlamlı derecede yüksek olduğu bulunmuştur. $(\mathrm{p}=0,001)$. Sürekli bir ilaç kullanmayan katılımcıların sağlık okur-yazarlığı puanı, ilaç kullananlara göre anlamlı derecede yüksek bulunmuştur( $\mathrm{p}=0,002)$.

Sonuç: Kronik hastalı̆̆ı olan menopoz dönemindeki kadınlarda eğitimin ve yüksek gelir düzeyi gibi faktörler sağlık okuryazarlığını olumlu yönde etkilemektedir.

Anahtar kelimeler: Sağlık okuryazarlı̆̆ı, kronik hastalık, menopozal dönem, kadın.

Received Date / Geliş tarihi: 25.06.2018, Accepted Date / Kabul tarihi: 06.08.2018

${ }^{1}$ Çankırı Karatekin Üniversitesi, Sağlık Bilimleri Fakültesi Hemşirelik Bölümü, Çankırı, TÜRKIYE.

${ }^{2}$ Çankırı Devlet Hastanesi, Çankırı, TÜRKIYE.

*Address for Correspondence / Yazışma Adresi: Derya Kaya Şenol, Çankırı Karatekin Üniversitesi, Sağlık Bilimleri Fakültesi

Hemşirelik Bölümü, Çankırı, TÜRKIYE.

E-mail: dderya kaya@ hotmail.com

Kaya Şenol D, Bulantekin Düzalan Ö, Sarıkaya S, Özen B. Kronik Hastalığı Olan Menopozal Dönemdeki Kadınlarda Menopoz Algısı ve Sağlık Okur Yazarlığının Değerlendirilmesi. TJFMPC, 2019;13(1): 14-21.

DOI: $10.21763 /$ tjfmpc.428217 


\section{GíRIŞ}

Sağlık okuryazarlığı, bireyin sağlığın korunması, sağlığın iyileştirilmesi ve bozulması durumunda tedavi hizmetlerinden yararlanma gibi temel sağlık bilgileri ve hizmetleri edinme, yorumlama ve kullanma kapasitesi olarak tanımlanabilir. ${ }^{1}$ Sağlık okuryazarlığı, Dünya Sağlık Örgütü'ne (DSÖ) göre, bireylerin sağlığını korumak ve geliştirmek için bilgiye ulaşma, anlama, bu bilgiyi kullanma konusunda bilişsel-sosyal becerileri ve motivasyon düzeyleridir. ${ }^{2}$

Sağlık okuryazarlığı seviyesinin, yaşlı nüfus, eğitim düzeyi düşük olanlar, yoksullar, azınlıklar ve yaşadıkları ülkenin dilini iyi kullanamayanlarda daha düşük olduğu belirtilmektedir. ${ }^{3}$ Düşük sağlık okuryazarlığ1 seviyesinin, sağlık bilgisini anlama becerilerinde güçlüklere neden olduğu, süreçleri ve talimatları yerine getirmede zorluklar ve sağlık hizmetlerinin etkin kullanılamaması ile ilgili problemlere neden olduğu bilinmektedir., ${ }^{4,-6}$ Düşük sağlık okuryazarlığı, nüfusun önemli bir kısmını etkileyen, sağlığı azaltan ve / veya hastalığın seviyesini ve etkisini artıran önemli bir halk sağlığı sorunudur. Daha düşük fonksiyonel sağlık okuryazarlığı becerileri, yaşlılarda daha yüksek mortalite, artan hastaneye yatma ve daha büyük acil bakım kullanımı gibi tıbbi hizmetlerin 4-6 kez daha fazla kullanılması ile ilişkilidir. $^{7}$ Ayrıca ilaçları uygun şekilde kullanma, ${ }^{8}$ kalp yetmezliği ve astım gibi uzun dönemli hastalıkları yönetmede zorluk yaşama gibi durumlara neden olmaktadır. ${ }^{9}$

Menstruasyonun bitişi olarak kabul edilen menopoz; kadınların hormonal, fizyolojik ve psikolojik değişiklikler yaşadığı bir dönemdir. Menopoz, tüm kadınlar için doğal yaşlanma sürecinin bir parçası olmasına rağmen, menopozal döneme geçiş deneyimi bireysel farklılıklar gösterir. Semptomlar, fiziksel ve psikolojik olabilir ve yaşam kalitesini pek çok açıdan olumsuz yönde etkileyebilir. ${ }^{10-12}$ Kadınların bu dönemde erkeklere göre daha fazla ve daha uzun süreli hastalıklara maruz kaldığı görülmektedir. Yaşamın bu evresi fizyolojik olarak normal değişiklikleri içerirken, bazı kadınlar için endişe ve artan hastalıklara neden olmaktadır. ${ }^{13}$ Menopoz, kardiyovasküler sistem, eklem ve kas problemlerinin yanı sıra vazomotor ve ürogenital semptomların ve hastalıklarının artması ile ilişkilidir. ${ }^{14}$ Ruhsal hastalık, özellikle de depresif belirtiler yaşamın bu fazında belirgin bir artış gösterir. ${ }^{15}$ Dolayısıyla, menopoz dönemindeki kadınlar, özel gereksinimleri olan özel bir grup olarak ele alınmalıdır.
Çalışma, menopozal dönemdeki kadınların sağlık okuryazarlığ d durumlarını belirlemek amacıyla tanımlayıcı olarak yapılmıştır.

\section{YÖNTEM}

Araştırmada evrenini, Haziran-Aralık 2016 tarihleri arasında Çankırı devlet Hastanesi'ne başvuran en az 6 ay önce kronik hastalık tanısı alan (diyabet, kalp hastalıkları...), konuşmaduyma-görme engeli olmayan kadınlar oluşturmuştur. Örneklemi ise, Çankırı Devlet Hastanesi Dahiliye kliniğinde yatarak tedavi gören, okuma-yazma bilen, araştırma sorularını algılama ve cevaplamada sorun yaşamayacak düzeyde bilişsel yeterliliği olan, konuşma-duyma-görme engeli olmayan, araştırmaya katılmayı kabul eden ve menopozal dönemde olan kadınlar (175 kişi) oluşturmuştur.

Araştırmanın verileri; Demografik bilgi formu ve Yetişkin Sağlık okuryazarlığı ölçeği (YSOÖ) kullanılarak toplanmıştır. YSOÖ, 2014 yilında Ayşe Sezer tarafindan geliştirilmiş olup, geçerlik ve güvenirliği yapılmıştır. Ölçek, yetişkin bireylerin sağlık okuryazarlığı konusundaki yeterliliğini belirlemeye yönelik, sağlık bilgileri ve ilaç kullanımı ile ilgili toplam 22 madde ve 1 adet vücuttaki organların yerini bilme ile ilgili şekli içermektedir. Ölçekte yer alan soruların 13 tanesi evet/hayır, 4 tanesi boşluk doldurma, 4 tanesi çoktan seçmeli, 2 tanesi eşleştirmelidir. Soruların puanlaması her soru tipi için ayrı ayrı yapılmıştır. Evet/hayır yanıt tipindeki sorularda, pozitif ifadeleri işaretleyenlere 1, negatif ifadeleri işaretleyenlere 0 puan, boşluk doldurma tipindeki sorularda doğru yanıta 1, yanlış yanıta 0 puan verilmiştir. Çoktan seçmeli sorularda, iki ve ikiden fazla doğru yanıt işaretleyenlere 1 puan, hiç bilmeyenlere ya da doğru ile birlikte yanlış yanıt işaretleyenlere 0 puan verilmiştir. Eşleştirme tipindeki sorularda ise, ikiden fazla doğru eşleştirenlere 1 , diğerlerine 0 puan verilmiştir. Ölçekten alınabilecek puanlar 0-23 arasında değişmektedir. Ölçekten alınan puan arttıkça sağlık okuryazarlık düzeyi artmaktadır. ${ }^{16}$

Araştırmaya başlamadan önce, Çankırı Karatekin Üniversitesi Etik Kurulundan etik onay (13.10.2016-2016/03) ve çalışmanın yapıldığı kurumdan yazılı izin alınmıştır. Ayrıca çalışmaya katılan tüm kadınlara, çalıșmanın amacı ve elde edilen sonuçların başka bir amaçla kullanılmayacağı hakkında bilgi verildikten sonra sözlü onayları alınmıştır. Bu çalışmada elde edilen veriler, IBM SPSS Statistics Version 20 paket 
programı ile analiz edilmiştir. Değişkenlerin, normal dağılım gösterip göstermedikleri araştırılırken Kolmogorov Smirnov'dan yararlanılmıştır. Gruplar arasındaki farklılıklar incelenirken, normal dağılım göstermeyen değişkenler için 2 gruplu karşılaştırmalarda Mann Whitney U Testinden, 2'den fazla boyutlu karşılaştırmalar için ise Kruskal Wallis $\mathrm{H}$ Testinden yararlanılmıştır. Sonuçlar yorumlanırken anlamlılık düzeyi $\mathrm{p}<0,05$ olarak kullanılmıştır.

\section{BULGULAR}

Kadınların yaş ortalamasının $\quad 51,7 \pm 9,4$ (Min:41, Maks:61) olduğu, \%32,5'inin okuryazar olmadığı, \%8,5'inin lise ve üzeri düzeyde eğitim aldığı, \%87,4'ünün ev hanımı olduğu, \%94,3'ünün sosyal güvencesinin bulunduğu, \%52,6'sının gelirinin giderine denk olduğu saptanmıştır. Kadınların genel sağlık alışkanlıklarına bakıldığında, \% 91,4'ünün sürekli kullandığı bir ilacı olduğu ve \%10,9'unun sigara kullandiğı belirlenmiştir (Tablo1). Çalışmada, kadınların ortalama ilk evlilik yaşı $17,5 \pm 3,6$, ilk adet yaşı $13,1 \pm 1,9$, menapoz yaşı $47,1 \pm 5,8$ olarak belirlenmiştir. Doğurganlık özelliklerine bakıldığında, ortalama gebelik sayısı $5,5 \pm 3,3$, normal doğum sayıs $3,9 \pm 2,1$, evde doğum sayısı 3,8 $\pm 2,5$ idi (Tablo 2). Çalışmada, kadınların ortalama ilk evlilik yaşı $17,5 \pm 3,6$, ilk adet yaşı $13,1 \pm 1,9$, menapoz yaşı $47,1 \pm 5,8$ olarak belirlenmiştir. Doğurganlık özelliklerine bakıldığında, ortalama gebelik sayıs $5,5 \pm 3,3$, normal doğum sayıs $3,9 \pm 2,1$, evde doğum sayıs $3,8 \pm 2,5$ idi (Tablo2).

\section{Tablo 1. Kadınların sosyo-demografik ve genel sağlık özellikleri}

\begin{tabular}{|c|c|c|c|}
\hline \multicolumn{2}{|c|}{ Tanımlayıcı özellikler } & $\mathbf{n}$ & $\%$ \\
\hline \multirow{4}{*}{ Eğitim durumu } & Okuryazar değil & 57 & $(32,5)$ \\
\hline & Okuryazar & 56 & $(32,2)$ \\
\hline & İlköğretim & 47 & $(26,8)$ \\
\hline & Lise ve üzeri & 15 & $(8,5)$ \\
\hline \multirow{4}{*}{ Meslek } & Ev hanımı & 153 & $(87,4)$ \\
\hline & Memur & 4 & $(2,3)$ \\
\hline & İşçi & 3 & $(1,7)$ \\
\hline & Emekli & 15 & $(8,6)$ \\
\hline \multirow{2}{*}{ Sosyal düvence } & Evet & 165 & $(94,3)$ \\
\hline & Hayır & 10 & $(5,7)$ \\
\hline \multirow{3}{*}{ Ekonomik durum } & Gelir giderden az & 65 & $(37,1)$ \\
\hline & Gelir gidere denk & 92 & $(52,6)$ \\
\hline & Gelir giderden fazla & 18 & $(10,3)$ \\
\hline \multirow{2}{*}{ Sürekli kullanılan bir ilaç } & Var & 160 & $(91,4)$ \\
\hline & Yok & 15 & $(8,6)$ \\
\hline \multirow{3}{*}{ Sigara kullanımı } & Var & 19 & $(10,9)$ \\
\hline & Yok & 156 & $(89,1)$ \\
\hline & Toplam & 175 & $(100.00)$ \\
\hline
\end{tabular}

Tablo 2. Kadınların obstetrik ve jinekolojik özellikleri (n:175)

\begin{tabular}{|c|c|c|c|}
\hline Obstetrik ve jinekolojik özellikler & Mean \pm ss & Min & Max \\
\hline Evlilik yaşı & $17,5 \pm 3,6$ & 10 & 33 \\
\hline İlk adet yaşı & $13,1 \pm 1,9$ & 9 & 25 \\
\hline Menapoz yaşı & $47,1 \pm 5,8$ & 28 & 56 \\
\hline Gebelik sayısı & $5,5 \pm 3,3$ & 1 & 18 \\
\hline Canlı doğum sayısı & $3,7 \pm 1,8$ & 1 & 10 \\
\hline Normal doğum sayısı & $3,9 \pm 2,1$ & 1 & 11 \\
\hline Düşük-kürtaj sayısı & $2,5 \pm 1,6$ & - & 8 \\
\hline Ölü doğum sayısı & $1,9 \pm 1,3$ & - & 8 \\
\hline Evde yapılan doğum sayısı & $3,8 \pm 2,5$ & - & 11 \\
\hline
\end{tabular}




\begin{tabular}{|c|c|c|c|c|c|c|c|c|}
\hline \multirow{2}{*}{\multicolumn{2}{|c|}{ Kadınların Özellikleri }} & \multicolumn{7}{|c|}{ Ölçek puanı } \\
\hline & & $\mathbf{n}$ & $\%$ & Mean \pm ss & Min. & Max. & $\mathbf{H}, \mathbf{z}$ & $\mathbf{p}$ \\
\hline \multirow{4}{*}{ Eğitim durumu } & Okuryazar değil & 57 & 32,6 & $8,3 \pm 1,0$ & 1 & 22 & \multirow{4}{*}{ H:41,107 } & \multirow{4}{*}{$0,001 *$} \\
\hline & Okuryazar & 56 & 32,0 & $10,1 \pm 3,0$ & 3 & 22 & & \\
\hline & İlköğretim & 47 & 26,7 & $10,9 \pm 2,0$ & 2 & 19 & & \\
\hline & Lise ve üzeri & 15 & 8,7 & $15,3 \pm 10,0$ & 1 & 22 & & \\
\hline \multirow{3}{*}{$\begin{array}{c}\text { Ekonomik } \\
\text { durum }\end{array}$} & Gelir giderden az & 65 & 37,1 & $9,3 \pm 1,0$ & 1 & 22 & \multirow{3}{*}{$\mathrm{H}: 14,560$} & \multirow{3}{*}{$0,001 *$} \\
\hline & Gelir gidere denk & 92 & 52,6 & $10,1 \pm 2,0$ & 2 & 22 & & \\
\hline & Gelir giderden fazla & 18 & 10,3 & $13,6 \pm 6,0$ & 6 & 22 & & \\
\hline \multirow{2}{*}{$\begin{array}{c}\text { Sürekli } \\
\text { kullandığı bir } \\
\text { ilaç }\end{array}$} & Var & 160 & 91,4 & $10,0 \pm 3,8$ & 1 & 22 & \multirow[b]{2}{*}{$Z:-2,976$} & \multirow[b]{2}{*}{$0,003 * *$} \\
\hline & Yok & 12 & 8,6 & $13,5 \pm 4,1$ & 4 & 20 & & \\
\hline \multirow{2}{*}{$\begin{array}{c}\text { Sigara } \\
\text { kullanımı }\end{array}$} & Kullanıyor & 16 & 10,7 & $13,3 \pm 4,4$ & 4 & 22 & \multirow[b]{2}{*}{ Z:-3,068 } & \multirow[b]{2}{*}{$0,002 * *$} \\
\hline & Kullanmiyor & 156 & 89,3 & $9,9 \pm 3,8$ & 1 & 22 & & \\
\hline
\end{tabular}

*Kruskal Wallis H Test, **Man Whitney U

Tablo 4. Kadınların menapozal döneme ait özelliklerine göre sağlık okur-yazarlığı ölçeği puan ortalamaları

\begin{tabular}{|c|c|c|c|c|c|c|c|c|}
\hline \multirow{2}{*}{\multicolumn{2}{|c|}{ Kadınların özellikleri }} & \multicolumn{7}{|c|}{ Ölçek puanı } \\
\hline & & $\mathbf{n}$ & $\%$ & Mean \pm ss & Min & Max & $\mathbf{H}, \mathbf{z}$ & $\mathbf{p}$ \\
\hline \multirow{5}{*}{$\begin{array}{c}\text { Kadının menapoz } \\
\text { dönemini nasıl algıladığı }\end{array}$} & Doğal bir süreç & 75 & 42,9 & $9,9 \pm 4,1$ & 1 & 20 & \multirow{5}{*}{ H:0,623 } & \multirow{5}{*}{0,960} \\
\hline & Kadınlığın yok olması & 30 & 17,1 & $10,9 \pm 5,1$ & 4 & 22 & & \\
\hline & Üretkenliğin bitmesi & 11 & 6,3 & $10,5 \pm 4,3$ & 3 & 17 & & \\
\hline & Yaşlandığını hissetme & 8 & 4,6 & $10,1 \pm 3,2$ & 6 & 15 & & \\
\hline & Cevapsız & 51 & 29,1 & $10,1 \pm 3,1$ & 5 & 18 & & \\
\hline \multirow{2}{*}{$\begin{array}{l}\text { Menapoz öncesi dönemde } \\
\text { menopoza yönelik bilgi } \\
\text { alma }\end{array}$} & Evet & 68 & 38,9 & $10,9 \pm 4,3$ & 4 & 22 & \multirow{2}{*}{$\mathrm{H}: 3,862$} & \multirow{2}{*}{0,145} \\
\hline & Hayır & 107 & 61,1 & $9,6 \pm 3,5$ & 1 & 22 & & \\
\hline \multirow{2}{*}{$\begin{array}{c}\text { Adetten kesildikten sonra } \\
\text { oluşan yakınmalar nedeni } \\
\text { ile herhangi bir sağllk } \\
\text { kuruluşuna başvurma }\end{array}$} & Evet & 59 & 33,2 & $10,7 \pm 4,1$ & 3 & 22 & \multirow{2}{*}{ z:-1,134 } & \multirow{2}{*}{0,257} \\
\hline & Hayır & 116 & 66,8 & $9,9 \pm 3,8$ & 1 & 22 & & \\
\hline
\end{tabular}

*Kruskal Wallis H Test, **Man Whitney U

Kadınların sağlık okuryazarlığı puan ortalamaları 10,2 $\pm 3,9$ olarak belirlenmiştir. Sağlık okur-yazarlığı puan ortalamaları ile eğitim durumu incelendiğinde, aralarında istatistiksel olarak anlamlı bir farklılık bulunduğu belirlenmiştir $(\mathrm{p}=0,001)$. Lise ve üzeri düzeyde mezun olan kadınların, sağlık okur-yazarlığı puan ortalamaları okuryazar olmayan, okuryazar ve ilköğretim mezunu katılımcilara göre, ilköğretim mezunu ve okuryazar olan katılımcıların sağlık okuryazarlı̆g puan ortalamaları ise okuryazar olmayan katılımcilara göre anlamlı derecede yüksek bulunmuştur $(p=0,001)$. Kadınların sağlık okur-yazarlığı puan ortalamaları ile ekonomik durum değişkeni arasındaki ilişkiye bakıldığında, geliri giderden fazla olanların puan ortalamalarının, geliri gidere denk ve geliri giderden az olanlara göre anlamlı derecede yüksek bulunmuş ve farkın istatistiksel olarak anlamlı olduğu görülmüştür $(\mathrm{p}=0,001)$.

Çalışmada, sürekli kullandığı bir ilaç olmayan katılımcıların sağlık okur-yazarlığ ortalamalarının, sürekli kullandığı bir ilaç olan katılımcılara göre anlamlı derecede yüksek olduğu ve farkın istatistiksel açıdan anlamlı olduğu saptanmıştır $\quad(p=0,003)$. Sigara kullanımı ile sağlık okur-yazarlığı ilişkisi incelendiğinde ise, sigara kullananlarda puan ortalamasinın, sigara kullanmayan katılımc1lara göre istatistiksel olarak anlamlı derecede yüksek olduğu belirlenmiştir $(\mathrm{p}=0,002)$ (Tablo 3). 
Kadınlara, menopoz dönemini nasıl algıladıkları sorulduğunda, \%42,9’u “doğal, normal bir süreç" olarak gördüğünü ifade ederken, \%17,1'i "kadınlık özelliklerinin yok olması" şeklinde cevap verdi. Katılımcıların $\% 66,8$ 'i, adetten kesildikten sonra oluşan yakınmalar nedeni ile bir sağlık kuruluşuna başvurmadığını belirtirken, \%61,1'inin menopoz öncesi dönemde menopoza yönelik bilgi almadığ ${ }_{1}(\mathrm{p}=0,145)$, bilgi alanların ise yaklaşık yarısının $(\% 53,9)$ bu bilgiyi hekimden aldığ 1 belirlenmiştir. Kadınların sağlık okuryazarlığı puan ortalamaları ile menopoza yönelik bilgi alma durumu ve menopoz dönemini algılama durumları arasında istatistiksel olarak anlamlı bir farklılık bulunmamaktadır $\quad(p=0,960) . \quad$ İstatistiksel olarak anlamlı olmamakla birlikte, cevaplayanlar arasında menopoza yönelik bilgi alanların ve menopoz dönemini kadınlık özelliklerinin yok olması olarak algılayanların, Sağlık okur-yazarlığı ölçeği puan ortalamalarının daha yüksek olduğu belirlenmiştir. Adetten kesildikten sonra oluşan yakınmalar nedeniyle, sağlık kuruluşuna başvurma durumları ile sağlık okur-yazarlığı ölçeği puan ortalamaları karşılaştırıldığında ise, aralarında istatistiksel olarak anlamlı bir farklılık bulunmazken ( $p=0,257)$, oluşan yakınmalarla herhangi bir sağlık kuruluşuna başvuranların sağlık okur-yazarlığı ölçeği puanı daha yüksek bulunmuştur (Tablo 4).

\section{TARTIŞMA}

Çalışmada, kadınların sağlık okuryazarlığı puan ortalamaları 10.2 \pm 3.9 olduğu görülmüştür. Yapılan farklı çalışmalarda da, sağlık okuryazarlığı yaşlı nüfusun \%85.1'inde "sorunlu veya yetersiz" olarak belirtilmektedir. ${ }^{17}$ Farklı ölçekler kullanılarak yapılan araştırmalarda, yetersiz okuryazarlık seviyesinin \%22 ile \%29 arasında olduğu bildirilirken, ${ }^{18}$ bir başka sistematik derlemede, bu oranının \%34 ile \%59 arasında olduğu bildirilmektedir. ${ }^{19}$ Sonuçlarımız, literatürle benzerlik göstermektedir.

Eğitim ve gelir, sağlığın belirlenmesinde anahtar faktörlerdir. ${ }^{20}$ Kronik hastalıklar ve düşük yaşam beklentileri yaş, cinsiyet, 1rk ve coğrafi konumdan bağımsız olarak düşük gelirli toplumlarda daha yaygındır. ${ }^{21}$ Ayrıca, düşük gelirli nüfuslarda sağlık hizmetlerine erişim daha kısıtlıdır. ${ }^{22} \mathrm{Ek}$ olarak, düşük eğitim seviyeleri daha kötü sağlık, daha fazla stres ve düşük öz-yeterlilik ile ilişkilidir. Daha da önemlisi, düşük eğitim, genel okuryazarlık ve sağlık okuryazarlığ seviyelerini azaltma eğilimindedir ve bu da öz- yönetim becerilerini olumsuz etkilemektedir. ${ }^{20}$ Çalışmada, sağlık okur-yazarlığı puan ortalamaları ile eğitim durumu incelendiğinde, eğitim seviyesi azaldıkça sağlık okur-yazarlığ puan ortalamalarının da paralel olarak anlamlı derecede azaldığı görülmüştür. Yapılan benzer çalışmalarda da, eğitimi seviyesi düşük olan kadınlarda sağlık okuryazarlığ düşük olduğu belirtilmektedir. ${ }^{23}$

Düşük gelir ve düşük sağlık okuryazarlığı, hem daha kötü sağlık sonuçları hem de daha yüksek kronik hastalık oranları ile ilişkilidir. Kadınların sağlık okur-yazarlığı puan ortalamaları ile ekonomik durum değişkeni arasındaki ilişkiye bakıldığında, geliri giderden fazla olanların puan ortalamalarının geliri giderine denk ve geliri giderden az olanlara göre anlamlı derecede yüksek olduğu görülmüştür. Küresel olarak artan kronik hastalıkların önlenmesi, sağlık giderlerinin azaltılmasında ve bireyin yaşam kalitesinin artırılmasında önemli bir stratejidir. $^{20}$

Sağlık okuryazarlığı düzeyi, bireyin kronik hastalıkların yönetiminde ve ilaç uyumunda önemlidir. Özellikle, yaşlı ve düşük sosyoekonomik düzeyi olan bireylerde sağlık okuryazarlığı düşüktür ve bu bireylerinde ilaç uyumunda zorluk yaşanmaktadır. ${ }^{24}$ Çalışmada, sürekli kullandığı bir ilaç olmayan bireylerin sağlık okur-yazarlığı puan ortalamalarının, sürekli kullandığ 1 bir ilaç olan bireylere göre anlamlı derecede yüksek olduğu saptanmıştır. Düşük sağlık okuryazarlığı olan bireyler, kronik hastalıkların ilaçla yönetiminde daha fazla güçlük çekmektedir. ${ }^{25}$ Daha yüksek hastaneye başvuru ve yatış oranlarına da rastlanmaktadır. ${ }^{26}$

Sağlık okuryazarlığı düşük olan yetişkinlerin, yüksek riskli sağlık davranışlar yapma olasılıkları daha yüksektir. ${ }^{27,28}$ Çalışmada, sigara kullanımı ile sağlık okuryazarlığı ilişkisi incelendiğinde ise, sigara kullananlarda puan ortalamasının, sigara kullanmayan katılımcılara göre istatistiksel olarak anlamlı derecede yüksek olduğu belirlenmiştir. Yapılan benzer bir çalışmada da, sigara kullananların sağlık okur-yazarlığ puan ortalamalarının kullanmayanlara göre anlamlı derecede yüksek olduğu belirtilmektedir. ${ }^{29}$ Literatüre baktığımızda farklı sonuçlarla karşılaşmaktayız. Çalışmalarda, yaşlı erişkinlerde düşük sağlık okur-yazarlığı ve mevcut sigara içme durumu arasında anlamlı bir ilişki olduğunu bildirirken; ${ }^{30}$ düşük sağlık okur-yazarlığı ve sigara içme durumu arasında bir ilişki olmadığ 1 
da belirtmektedir. ${ }^{31}$ Yapılan bir başka çalışmada ise, sigaraya tekrar başlamaya neden olduğu bilinen yaş, cinsiyet, 1rk/etnisite, eğitim, gelir, ilişki durumu gibi demografik ve sosyo-ekonomik faktörler kontrol edildiğinde dahi, düşük sağlık okur-yazarlığı ve sigara içimi arasında ilişki olduğu belirtilmektedir. ${ }^{32}$ Çalışma, sonuçlarımızdaki farklılığın sigara kullanımını etkileyen yaş, cinsiyet, ırk, eğitim, gelir durumu gibi demografik ve sosyoekonomik faktörlerden etkilendiği düşünülmektedir.

Sağlık okuryazarlığının düşük olması, kişinin doğru bilgi ve hizmete ulaşma becerisini, bu hizmeti kullanabilme yeteneğini, kaynakların doğru kullanılmasını, kendi sağlığı ve toplum sağlığı üzerinde yetkin olmasını zorlaştırır. ${ }^{33}$ Çalışma sonuçlarında, menopoza yönelik bilgi alanların ve menopoz dönemini kadınlık özelliklerinin yok olması olarak algılayanların, sağlık okur-yazarlığı puan ortalamaları daha yüksek belirlenmiştir. Adetten kesildikten sonra oluşan yakınmalar nedeniyle, sağlık kuruluşuna başvuranların sağlık okur-yazarlığı puan ortalamaları daha yüksek bulunmuştur. Yapılan bazı araştırmalarda, sağlık okuryazarlığının yetersiz olması hastalanma riskinde artışa, tedavi yöntemlerini anlamada zorluğa ve hastaneye yatma oranında artışa neden olduğu belirtilmektedir. Ayrıca sağlık okuryazarlığı düşük olan bireyler, koruyucu sağlık hizmetlerini daha az kullanırken, bu bireylerde kanser gibi erken teşhis edilebilen durumlar için erken tarama sıklığında azalma, gereksiz hastane başvuruları nedeniyle sağlık hizmetleri harcamalarında ve yüksek morbidite ve mortalite oranlarında artı̧̧ görülmektedir. ${ }^{34,35}$

\section{Çalışmanın Sınırlılıkları}

Okuma-yazma bilmeyen, araştırma sorularını algılama ve cevaplamada sorun yaşayacak düzeyde bilişsel yeterliliği olmayan, konuşmaduyma-görme engeli olan kadınlar araştırma kapsamına alınmamıştır. Araştırma HaziranAralık 2016 tarihleri arasında Çankırı Devlet Hastanesi Dahiliye kliniğinde yatarak tedavi gören kronik hastalığı olan menapozal dönemdeki kadınlarda yapılmış olup evrene genellenemez.

\section{SONUÇ VE ÖNERİLER}

Kronik hastalığg olan menopoz dönemindeki kadınlarda, düşük eğitim seviyesi ve düşük gelir, sağlık sorunlarında oluşan yakınmalar nedeniyle sağlık kuruluşuna başvurmama ve sağlıkla ilgili konularda bilgi alınmaması, düşük sağlık okuryazarlığı ile ilişkilidir. Bu çalışma, menopozal dönemde sağlık okuryazarlığının değerlendirilmesinin önemini ortaya koymaktadır. Menopoza özgü sağlık okuryazarlığının değerlendirilmesi, kadınların menopoz semptomları için tıbbi bakım almaları, menopozal yakınmaları olan kadınların baş etme davranışlarını geliştirmeleri ve kronik hastalıkların yönetimi açısından yararlı olabilir.

Etik Kurul Onayı: Çankırı Karatekin Üniversitesi Etik Kurulundan çalışma için etik kurul onayı alınmıştır.

Hasta Onayı: Çalışmaya katılan tüm hastalardan sözlü onam alınmıştır.

Finansal Destek: Yazar tarafindan finansal destek almadığı bildirilmiştir.

\section{KAYNAKLAR}

1. Rowlands G. Health literacy. Hum Vaccin Immunother. 2014; 10:7, 2130-2135, DOI: 10.4161/hv.29603

2. World Health Organization. 7th Global conference on health promotion. Track themes: Track. 2009;1. Erişim tarihi: 15.03.2017,

http://www.who.int/healthpromotion/conf erenc es/7gchp/track2/en/

3. WHO regional office for Europe. Health literacy: the solid facts. 2013 [cited 04 Dec 2017]. Available from: http://www.euro.who.int/data/assets/pdf fi le/0008/ 190655/e96854.pdf. Erişim tarihi: 04 Kasim 2017.

4. Berkman ND, Sheridan SL, Donahue KE, et al. Health literacy interventions and outcomes: an updated systematic review. Evid Rep Technol Assess (Full Rep) 2011;199:1-941.

5. Heijmans M, Waverijn G, Rademakers, et al. Functional, communicative and critical health literacy of chronic disease patients and their importance for self-management. Patient Educ Counsel 2015;98: 41-48.

6. Friis $\mathrm{K}$, Lasgaard M, Osborne RH, Maindal HT. Gaps in understanding health and engagement with healthcare providers across common long-term conditions: a population survey of health literacy in Danish citizens. BMJ Open. 2016; 14;6(1):e009627. doi: 10.1136/bmjopen2015-009627.

7. Bostock S, Steptoe A. Association between low functional health literacy and mortality in older adults: longitudinal cohort study. BMJ 2012; 344:e1602; 
PMID:22422872;

http://dx.doi.org/10.1136/bmj. e1602.

8. Zhang NJ, Terry A, McHorney CA. Impact of health literacy on medication adherence: a systematic review and metaanalysis. Ann Pharmacother 2014; 48:74151; PMID:24619949; http://dx.doi. org/10.1177/1060028014526562.

9. Murray MD, Tu W, Wu J, Morrow D, Smith F, Brater DC. Factors associated with exacerbation of heart failure include treatment adherence and health literacy skills. Clin Pharmacol Ther 2009; 85:651657

10. P. Giannouli, I. Zervas, E. Armeni, K. Koundi, A. Spyropoulou, A. Alexandrou, A. Kazani, A. Areti, M. Creatsa, I. Lambrinoudaki, Determinants of quality of life in Greek middle-age women: a population survey, Maturitas 2012; 71: 154-161.

11. M. Suka, A. Taniuchi, S. Igarashi, N. Shimbashi, B. Ishizuka, The menopause week 2012 questionnaire survey: determinants of quality of life in Japanese middle-aged women. J Jap Menopause Soc 2013; 21:391-398.

12. Sukaa M, Taniuchi A, Igarashi S, Yanagisawaa H, Ishizukac B. Menopausespecific health literacy in Japanese women Maturitas 2016; 91:51-59.

13. J.E. Blumel, P. Chedraui, G. Baron, E. Belzares, A. Bencosme, A.Calle, et al.Menopausal symptoms appear before the menopause and persist 5 years beyond: a detailed analysis of a multinational study Climacteric, 2012; 15:(6) 542-551.

14. Moreau KL, Hildreth KL, Meditz AL, Deane KD, Kohrt WM. Endothelial function is impaired across the stages of the menopause transition in healthy women. J Clin Endocrinol Metab 2012; 97(12): 4692-4700.

15. Freeman EW, Sammel MD, Boorman DW, Zhang R. Longitudinal pattern of depressive symptoms around natural menopause JAMA Psychiatry, 2014;71(1):36-43.

16. Sezer A, Kadığlu H. Yetişkin Sağlık Okuryazarlığı Ölçeği'nin Geliştirilmesi. Anadolu Hemşirelik ve Sağlık Bilimleri Dergisi, 2014;17(3): 165-170.

17. Bozkurt H, Demirci H. Health literacy among older persons in Turkey, The Aging Male 2018; 10:1-6. https://doi.org/10.1080/13685538.2018.14 $\underline{37901}$

18. Berkman ND, Davis TC, McCormack L. Health literacy: what is it? J Health Commun 2010;15:9-19.
19. Serper M1, Patzer RE, Curtis LM, Smith SG, O'Conor R, Baker DW, Wolf MS. Health literacy, cognitive ability, and functional health status among older adults. Health Serv Res. 2014;49:12491267.

20. Schaffler J, Leung $\mathrm{K}$, Tremblay $\mathrm{S}$, Merdsoy L, Belzile E, Lambrou A, Lambert SD. The Effectiveness of SelfManagement Interventions for Individuals with Low Health Literacy and/or Low Income: A Descriptive Systematic Review J Gen Intern Med- 33(4):510-523. doi: 10.1007/s11606-017-4265-x. Epub 2018 Feb

21. Betancourt MT, Roberts KC, Bennett TL, Driscoll ER, Jayaraman G, Pelletier L. Monitoring chronic diseases in Canada: the Chronic Disease Indicator Framework. Chronic Dis Inj Can 2014, 34(1):1-30.

22. Dubay LC, Lebrun LA. Health, behavior, and health care disparities: disentangling the effects of income and race in the United States. Int J Health Serv 2012, 42:607-625.

23. Jarahi1 L, Asadi R, Hakimi H R. General health literacy assessment of Iranian women in Mashhad Electronic Physician 2017;9(11):5764-5769, DOI: http://dx.doi.org/10.19082/5764.

24. Kendir C, Akkaya K, Arslantaş İ, Kartal M. Dokuz Eylül Üniversitesi, Tip ve Hemşirelik Fakültelerine Başvuran Öğrencilerin, Sağlık Okuryazarlık Düzeyi. TJFMPC 2017;11(3) DOI: 10.21763/tjfmpc.336167.

25. Miller TA. Health literacy and adherence to medical treatment in chronic and acute illness: ameta-analysis. Patient Educ Couns 2016; 99:1079-86.

26. Baker DW, Gazmararian JA, Williams MV, Scott T, Parker RM, Green D, et al. Functional health literacy and the risk of hospital admission among medicare managed care enrollees. Am J Public Health 2002; 92:1278-83.

27. Stewart DW, Vidrine JI, Shete S, Spears CA, Cano MA, Correa-Fernández V, et al. Health literacy, smoking, and health indicators in African American adults. J Health Commun 2015;20(suppl 2):24-33.

28. Stewart DW, Cano MA, Correa-Fernández V, Spears CA, Li Y, Waters AJ, et al. Lower health literacy predicts smoking relapse among racially/ethnically diverse smokers with low socioeconomic status. BMC Public Health 2014;14:716. doi: 10.1186/1471-2458-14-716. 
29. Braun RT, Hanoch Y, Barnes AJ. Tobacco use and health insurance literacy among vulnerable populations: implications for health reform. BMC Health Serv Res. 2017;17(1):729. doi: 10.1186/s12913-017-2680-7.

30. Sudore RL, Mehta KM, Simonsick EM, Harris TB, Newman AB, Satterfield S, et al. Limited literacy in older people and disparities in health and healthcare access. J Am Geriatr Soc. 2006;54(5):770-776.

31. Baker DW, Wolf MS, Feinglass J, Thompson JA, Gazmararian JA, Huang J. Health literacy and mortality among elderly persons. Arch Intern Med. 2007;167(14):1503-1509.
32. Stewart DW, Adams CE, Cano M, CorreaFernandez V, Li Y, Waters AJ, et al. Associations between health literacy and established predictors of smoking cessation. Am J Public Health. 2013;103:e43-e49.

33. Mancusa MJ. Health Literacy: A concept/ dimensional analysis. Nursing and Health Sciences 2008; 10: 248-255.

34. Entwistle V, Williams B. Health literacy: The need to consider images as well as words. Health Expectations 2008;11(2): 99-101.

35. Eichler K, Wieser S, Brugger U. The costs of limited health literacy: A systematic review. Int J Public Health 2009;54(5): 313-324. 